\title{
CRISPR/CAS: EL FUTURO DE LA EDICIÓN GENÉTICA
}

\author{
CRISPR/Cas: the future of genetic editing
}

\section{EPISTEMUS}

ISSN: 2007-8196 (electrónico)

ISSN: 2007-4530 (impresa)

Daniel Mayboca Padilla 1

Daniel Flores Ruiz ${ }^{2}$

Recibido: 14 de octubre de 2016,

Aceptado: 13 de noviembre de 2016

Autor de Correspondencia:

LIC. DANIEL MAYBOCA PADILLA

Correo:daniel.mayboca.mc18@estudiantes.ciad.mx

\section{Resumen}

Desde el emprendimiento del proyecto del genoma humano y la posterior publicación de la secuencia de los más de 20,000 genes que lo comprende, el estudio de los genomas de muchos organismos, su manipulación y edición ha sido tendencia desde entonces, siendo propuestas y descubiertas nuevas herramientas que permiten la edición de los ácidos nucleicos. La función natural de CRISPR/Cas supone una defensa de las bacterias ante infecciones virales y terminó por ser un gran avance en el campo de las ciencias genómicas, permitiendo la edición genómica con mayor precisión al de las técnicas que le anteceden. Las aplicaciones de este sistema en las que se ha hecho énfasis en estos últimos años, son en la terapia génica y en el desarrollo de tratamientos antivirales. A pesar de los grandes avances de CRISPR/Cas, aún se requiere incrementar su especificidad para eliminar la aparición de mutaciones fuera del gen objetivo.

Palabras clave: CRISPR/Cas, Edición genómica, Terapia génica, Tratamiento antiviral.

\section{Abstract}

Since the project of the human genome and the subsequent publication of the sequence of more than 20,000 genes that comprise it, the study of the genomes of many organisms and their editing have been a trend since then, being proposed and discovered new tools that allow the editing of DNA. CRISPR/Cas system whose natural function is a defense of bacteria against viral infections, ended up being a breakthrough in the field of genomic sciences, allowing genomic editing at a level of precision greater than the techniques that preceded it. The applications of this system that has been emphasized in recent years, are gene therapy and the Development of alternative antiviral treatments. Despite the advances of CRISPR/Cas, it is still required to increase its specificity to eliminate the appearance of mutations outside the target gene.

Keywords: CRISPR/Cas, Genomic editing tool, Gene therapy, Antiviral treatment.

1 Centro de investigación en alimentación y desarrollo A.C. daniel.mayboca.mc18@estudiantes.ciad.mx

2 Centro de investigación en alimentación y desarrollo A.C. daniel.flores.mc18@estudiantes.ciad.mx 


\section{INTRODUCCIÓN}

Todos hemos oído hablar sobre el ácido desoxirribonucleico (ADN) y su papel en la herencia, los logros obtenidos en la mejora genética de muchos organismos y aspectos de importancia alrededor de los ácidos nucleicos. Los medios de comunicación nos permiten conocer sobre los hallazgos logrados en la ciencia, avances de gran importancia y de impacto en la actualidad, pero ¿cómo comenzó el ascenso de esta tecnología? O ¿sobre qué bases se cimientan dichos hallazgos? Demos un vistazo a los aportes que fueron fundamentales para el posterior avance de la biología y la ciencia.

\section{ANTECEDENTES HISTÓRICOS}

Lagenética fue de las primeras pistas en el conocimiento de los organismos, el entendimiento de su funcionamiento y manera en que operan en el mundo natural. A través de la historia con base al conocimiento científico disponible en momentos particulares se han logrado avances en la ciencia según las necesidades de cada tiempo. Una de las grandes ideas en biología fue expuesta por Gregor Mendel en 1865, un monje austriaco cuyos trabajos con guisantes de jardín (Pisum sativum) permitieron explicar el modo en que se transmitía la información genética de una generación a otra. A grandes rasgos Mendel descubrió que los individuos tienen dos alelos de cada gen y estos se separaban en gametos [1].

El término gen junto al de genotipo y fenotipo, no fue acuñado hasta 1909 por el botánico Wilhelm Johannsen, quien los describió como unidades físicas y funcionales de la herencia. No fue hasta trabajos posteriores de Thomas Morgan, que se mostró que los genes residen en cromosomas específicos, más adelante fue comenzado el primer mapa cromosómico de la mosca Drosophila, uno de muchos organismos modelo. Estos avances permitieron el conocimiento más específico de estas unidades hereditarias. Próximo a los 50's se habían hecho mutaciones genéticas que provocaban anormalidades metabólicas, siendo cada vez más convencedora la idea que los secretos moleculares de la vida se encontraban relacionadas a los ácidos nucleicos [2, 3].

Si bien se creía que las proteínas podrían ser las moléculas encargadas de la herencia por sus múltiples funciones, en 1952, Hershey y Chase experimentaron con bacteriófagos (virus que atacan bacterias), ellos descubrieron que el ADN era inyectado a las bacterias durante el proceso de infección mas no las proteínas, siendo uno de los experimentos que hicieron pensar que los ácidos nucleicos eran los responsables de la vida [4].

En esta época se comenzó una carrera mundial, la meta, determinar qué moléculas eran las encargadas de la herencia y de qué manera lo hacían, si bien era conocido que existían unidades relacionadas a los rasgos que eran heredables, también trabajos en el campo de las proteínas hacían pensar a los científicos, biólogos, bioquímicos, etc. que quizá las proteínas eran las biomoléculas encargadas de la herencia, siendo tan diversas, versátiles y de múltiples funciones en los organismos y la diversidad biológica. No fue hasta 1953 que James Watson y Francis Crick llegaron a la meta de esta carrera, elucidando con apoyo experimental de Rosalind Franklin, la estructura del ácido desoxirribonucleico (ADN), proponiendo el modelo tridimensional de la doble hélice, resolviendo así muchos de los misterios que hasta ese entonces permanecían ocultos $[5,6]$

Este es el punto crítico en el conocimiento de la genética, y el punto de partida a la biología molecular,

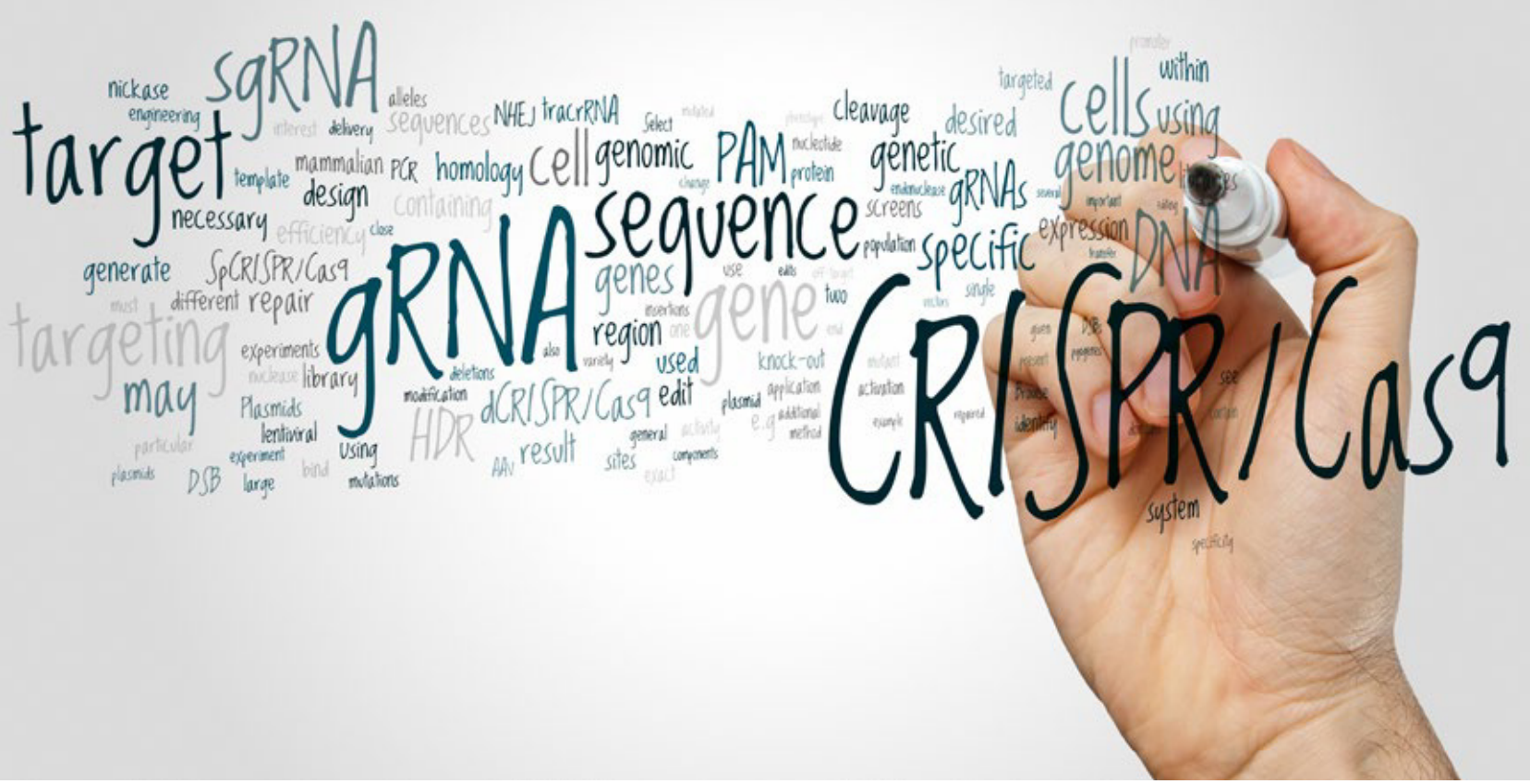




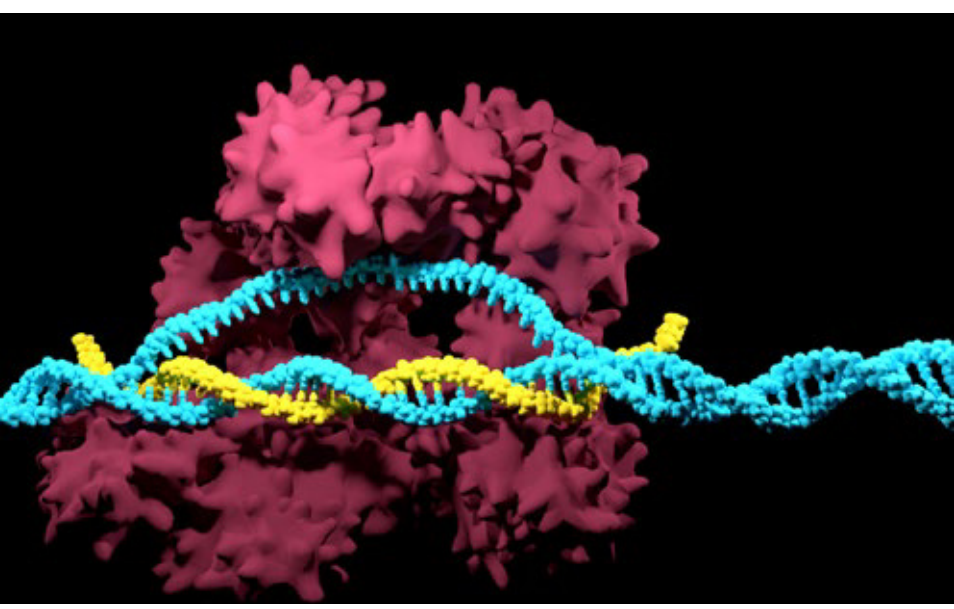

es aquí cuando el conocimiento de los ácidos nucleicos permitió el avance experimental, surgiendo lo que hoy conocemos como "Tecnología del ADN Recombinante". Esto se refiere al uso de moléculas de ADN para juntar material genético por distintos métodos, resultando así ADN recombinante, lo que es posible debido a que el material genético de todos los organismos comparte la misma estructura química, mismas características y propiedades fisicoquímicas, siendo la secuencia nucleotídica aquello que varía entre especies. De esta manera es posible combinar por diferentes técnicas, genes o secuencias nucleotídicas de interés en organismos, que de manera natural no se encuentran, lo anterior se conoce como ADN exógeno [7, 8].

Múltiples técnicas se han desarrollado para la manipulación del material genético, su modificación, expresión, entre otras cosas, y es aquí donde la biotecnología y la ingeniería genética han tenido tantas aplicaciones, desde la producción de la insulina humana recombinante hasta la mejora genética de cultivos, es todo un mundo de aplicaciones y de metodologías desarrolladas en función de un elemento común, el ADN, que es a donde está centrada la parte fundamental del presente artículo, donde será revisada una de las técnicas moleculares de mayor impacto en los últimos años, esta tecnología nos permite la edición de secuencias de ADN del genoma, pero a diferencia de otras, esta es de forma específica, tan así que podemos imaginarnos unas tijeras moleculares para cortar en puntos determinados e insertar los cambios deseados con mayor exactitud, esta herramienta molecular es conocida como CRISPR/Cas [8].

\section{Primeros descubrimientos}

En los 70's, la edición genómica fue posible por recombinación homóloga, si bien era un método complicado y con algunas desventajas en cuanto resultados positivos, permitía cierta precisión en la manipulación del genoma. Los inconvenientes del método guiaron al desarrollo de tecnologías que fueran más confiables, eficientes y precisas. Algunas de estas son las nucleasas con dedos de zinc, cuya función es interaccionar con los ácidos nucleicos provocando cortes en diferentes secuencias para una edición precisa del genoma $[9,10]$.

Debido a los altos costos de estas herramientas, el sistema CRISPR/Cas (repeticiones palindrómicas cortas agrupadas y regularmente interespaciadas) que fue inicialmente descubierto en el genoma de Escherichia coli [11] y de muchas Arqueas [12], ha sido utilizado como herramienta de edición genómica debido a que posee dos factores importantes para estos propósitos: una endonucleasa y una secuencia complementaria de reconocimiento.

\section{Mecanismos de CRISPR/Cas}

CRISPR/Cas ha sido identificado como un mecanismo de defensa en bacterias y arqueas. Koonin y Marakova (2006), propusieron que dichos microorganismos tenían la capacidad de integrar fragmentos de ADN viral (fagos) en su genoma, estos fragmentos al ser transcritos reconocían las secuencias del virus formando un complejo bicatenario que frenaba el proceso infectivo [13]. Posteriormente los datos experimentales de Barrangou (2007) [14], probaron que Streptococcus thermophilus era capaz de adquirir cierta inmunidad a un fago tras la incorporación de secuencias del virus, y la formación del complejo CRISPR/Cas [15].

El sistema se basa en la identificación y degradación de secuencias de ácidos nucleicos exógenos. Se compone de un ARNcr (secuencia CRISPR de 25 a 50 nucleótidos) y la endonucleasa Cas. Este ARNcr tiene la función de dirigir a Cas hacia su secuencia complementaria donde lleva el corte. Cabe mencionar que existen 3 sistemas CRISPR (I, II y III), donde CRISPR II ha sido el más empleado en la ingeniería genética por su alta eficiencia [16].

Para la activación de este sistema primero se debe adquirir la secuencia espaciadora por la exposición al patógeno, esto es logrado por el reconocimiento de una secuencia PAM, que se encuentra inmediatamente después de la secuencia de ADN dirigida por la nucleasa cas9. Como resultado de la incorporación de nucleótidos se obtiene una copia que termina flanqueando al nuevo fragmento (Figura 1).

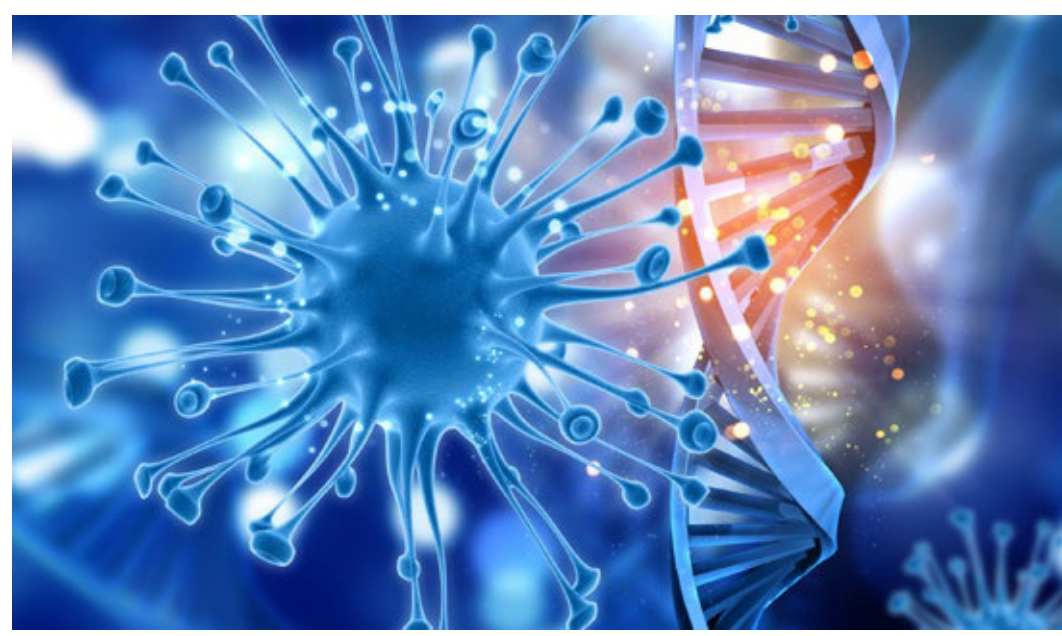


A continuación, comienza la transcripción del ARNcr el cual dirigirá a la endonucleasa. El sistema CRISPR II precisa de un segundo ARN (no codificante), el tracrARN, que es complementario a la secuencia palindrómica. La transcripción de este segundo ARN forma un dímero con este palíndromo que será reconocido por una RNasa III para generar un transcrito maduro (Figura 2).

Por último, Cas se asocia con el ARNcr maduro y forma el complejo CRISPR/Cas. Dicho ARN guiará al complejo a su diana por reconocimiento de la secuencia complementaria.

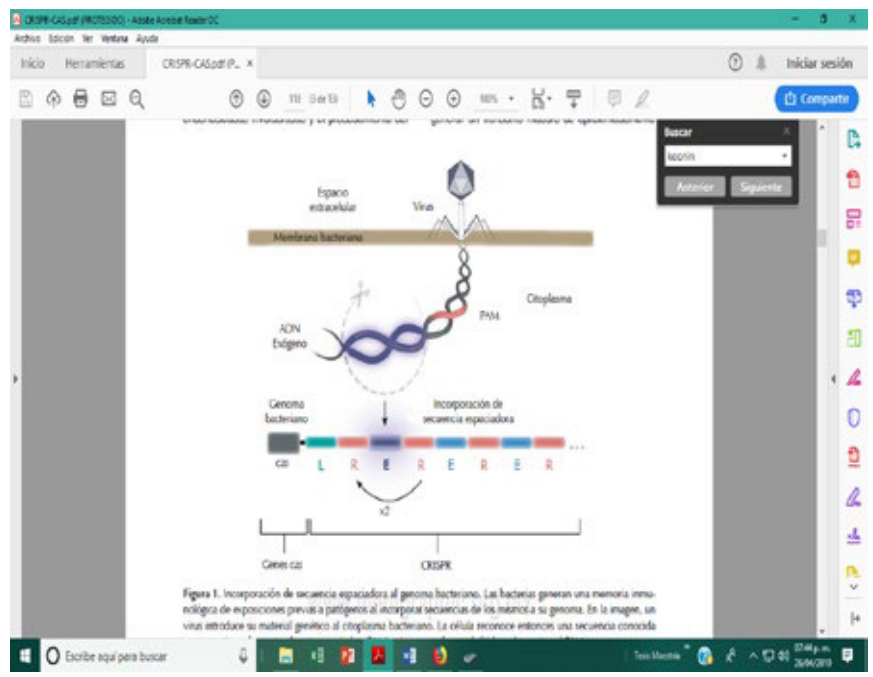

Figura 1. Activación del sistema CRISPR. Tomado de Lammoglia-Cobo et al., (2016).

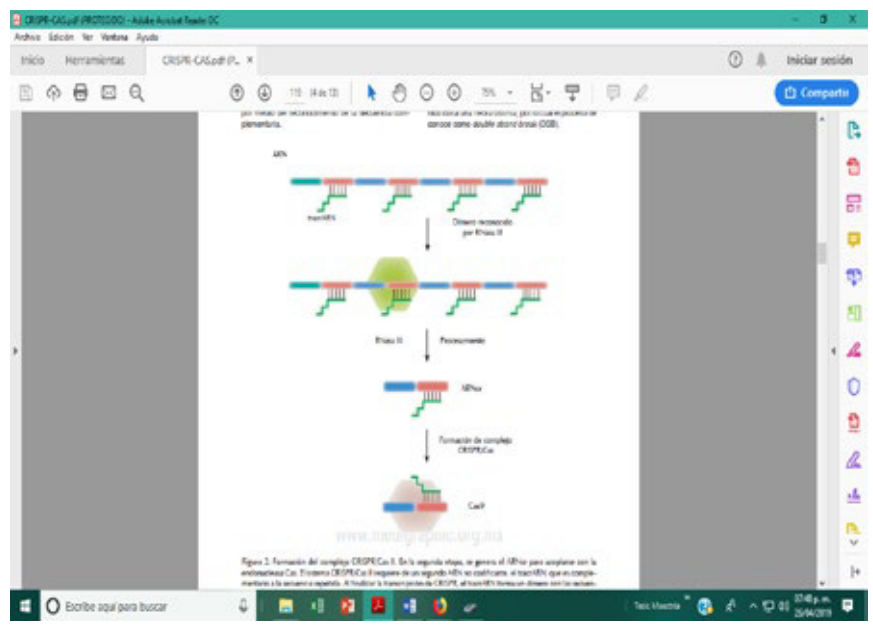

Figura 2. Formación del complejo CRISPR/Cas. Tomado de Lammoglia-Cobo et al., (2016).

\section{PRINCIPALES APLICACIONES DEL SISTEMA CRISPR/Cas}

CRISPR/Cas siendo un sistema tan especifico en el reconocimiento de genes diana, se ha utilizado como alternativa de edición génica pudiendo reemplazar métodos clásicos de biología molecular involucradas en el silenciamiento y mutación de genes de interés. Una de las estrategias para introducir este sistema a una célula diana (ya sea por electroporación, microinyección de ADN, biobalística o por transferencia directa de ADN) [17], es la de utilizar plásmidos que contengan a la endonucleasa Cas y una molécula semejante al complejo ARNcr/tracrARN conocido como ARN guía. De esta forma el complejo se puede ensamblar dentro de la célula y puede llevar a cabo su función en una secuencia complementaria a la del ARN guía [18]. las principales aplicaciones de este sistema en las que se ha hecho énfasis en estos últimos años, son en la terapia génica y en el desarrollo de tratamientos antivirales.

\section{Terapia génica}

Se entiende por terapia génica el tratamiento de enfermedades hereditarias o adquiridas mediante la transferencia de material genético en células del paciente, la finalidad de esta transferencia de material genético es restablecer una función celular que estaba defectuosa, introducir una nueva función o bien interferir con una función existente [19]. En el proceso de edición de un gen especifico con CRISPR/Cas están involucrados dos etapas. En la primera etapa el ARN guía reconoce la secuencia complementaria (gen de interés), esto permite que la nucleasa Cas9 genere una ruptura del gen diana. En la segunda etapa se activan al menos dos mecanismos naturales de reparación del ADN. El primer mecanismo consta en la reparación de una de las hebras utilizando una ADN polimerasa que introduce nucleótidos al azar en los puntos donde se localizan las lesiones (mecanismo de reparación por síntesis translesional). Este proceso conlleva a la pérdida de la función original del segmento de ADN reparado [20]. Un segundo mecanismo permite la incorporación de una secuencia concreta exactamente en el sitio original de corte. Para esto, se debe de proveer la secuencia de interés (como se hizo con el complejo de CRISPR/Cas) que se desee incorporar al ADN de la célula (mecanismo de reparación por unión de extremos no homólogos o por recombinación homologa, donde este último mecanismo es el más utilizado por las células eucariotas) [21].

Con experimentos recientes utilizando líneas celulares de osteosarcoma, se logró silenciar el gen que codifica para la proteína Cdk11 con el sistema CRISPR/Cas, aumentando la muerte celular, se disminuyó la migración y se redujo la invasión por células malignas [22]. En otros experimentos se logró corregir la función del gen Dmd involucrado en la distrofia muscular de Duchenne [23], el mismo procedimiento se llevó a cabo en líneas celulares intestinales de pacientes con fibrosis quística, donde se generó la modificación del gen que codifica para el receptor CFTR (Cystic Fibrosis Transmembrane Regulator), logrando recuperar el fenotipo normal [24]. A pesar de los resultados prometedores de CRISPR/Cas evaluado en líneas celulares que contienen genes que codifican proteínas defectuosas, se ha demostrado que este sistema 


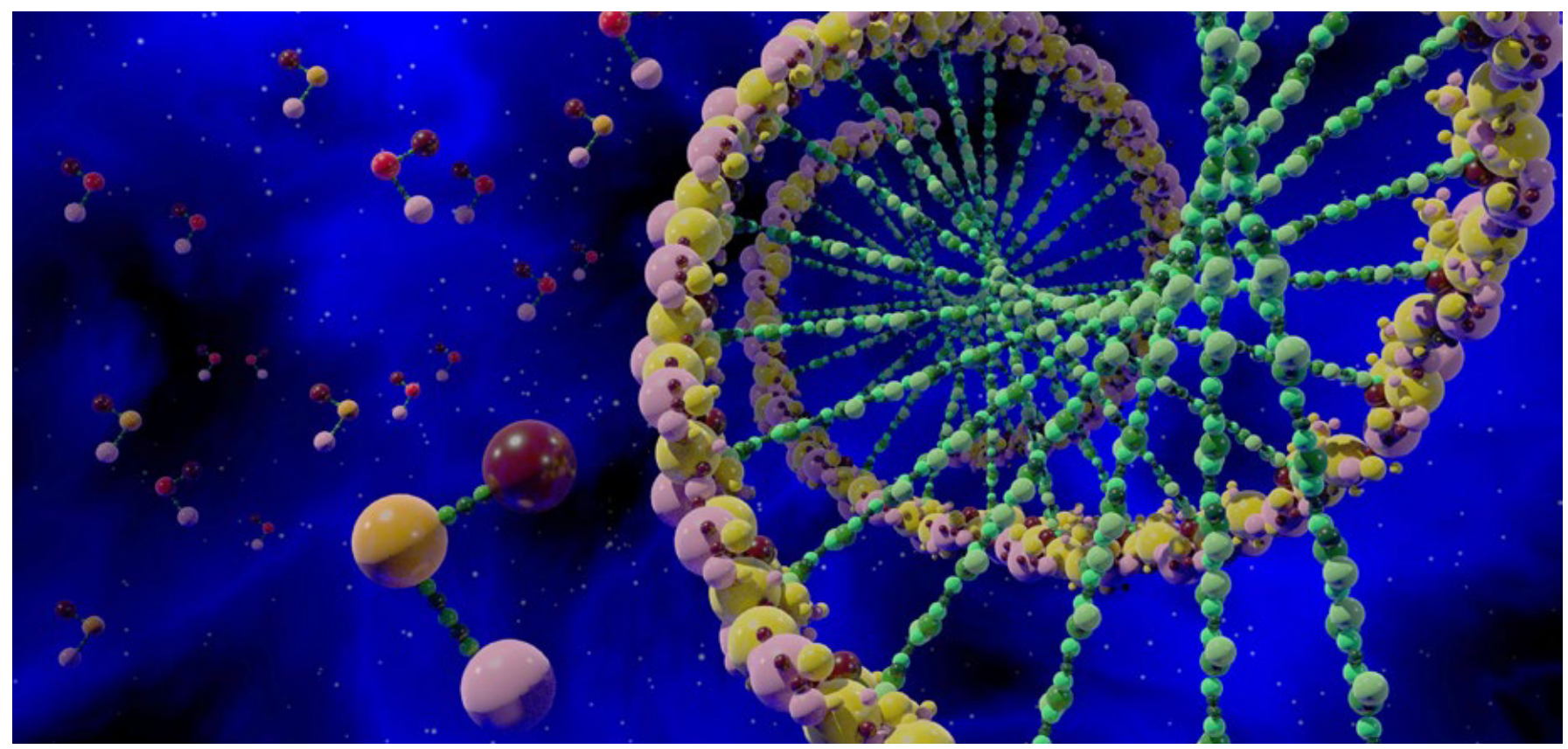

ha generado el estímulo del sistema inmune en ratones, esto representa problemas que se deben tomar en cuenta para su uso en terapia. En concreto, si el tratamiento terapéutico requiere la administración repetida de CRISPR/ Cas en pacientes puede producirse una reacción inmune a partir de la segunda exposición (inmunidad adaptativa) a CRISPR/Cas que comprometa su efectividad y ponga en peligro la vida del paciente a tratar [25].

\section{Tratamiento antiviral}

Los fármacos utilizados en este tipo de tratamiento se caracterizan por inhibir la acción de enzimas virales especificas (polimerasa, transcriptasa), esto permite controlar la viremia en los pacientes, pero no elimina las secuencias virales (ARN o ADN) que se encuentran integradas en las células infectadas, por lo que el virus permanece de forma latente en el organismo. Para evitar la activación del virus, es indispensable un tratamiento continuo de lo contrario, conllevara a la reactivación del virus generando un nuevo proceso de infección [26]. Uno de los tratamientos evaluados recientemente es el de trasplante de células pluripotenciales inducidas de pacientes con mutaciones en el receptor CCR5 (presente en los linfocitos T CD4), que es indispensable para la internalización del virus de inmunodeficiencia humana $(\mathrm{VIH})$. Los pacientes que presentan esta mutación generan una resistencia contra la infección por el VIH. Pero a pesar de los resultados prometedores obtenidos a través del trasplante de células pluripotenciales inducidas, sigue siendo un método ineficaz para erradicar el virus, esto se debe a la baja prevalencia de dicha mutación en la población mundial, además de que dicho tratamiento está restringido por la compatibilidad sanguínea entre el donador y el receptor [27].

La utilización de CRISPR/Cas como tratamiento antiviral sigue en desarrollo, pero bioensayos realizados en cultivos celulares infectados con el virus de la hepatitis B (VHB) han demostrado ser efectivos a la hora de reducir considerablemente la carga viral en alrededor de 4 días después de la administración del tratamiento. Aunque se espera que el corte del ADN vírico del VHB lleve a la mutagénesis o a la degradación del virión, aún se desconoce los mecanismos en el que el virus es eliminado dentro de la célula [28].

\section{CONCLUSION}

A pesar de los pocos años del descubrimiento $y$ desarrollo del sistema CRISPR/ Cas, este se ha posicionado como una de las herramientas enormemente prometedora para la erradicación de enfermedades hereditarias y la posibilidad de tratar enfermedades que hasta ahora se consideraban incurables. A pesar de esto, aun sigue en desarrollo métodos que permitan incrementar la especificidad del sistema para eliminar la aparición de mutaciones no puntuales y translocaciones cromosómicas no deseadas, asociadas con escisiones fuera del objetivo del ADN. 


\section{BIBLIOGRAFÍA}

[1] S. Freeman, "Fundamentos de biología," Catálogo Universitario y Profesional 2018, p. 28, 2010.

[2] D. D. de Tancredi, "El concepto de gen y cromosoma, conocimiento estructurante de la Biología. Algunas aportaciones desde la investigación en enseñanza de las ciencias," Revista de investigación, no. 59, pp. 189-220, 2006.

[3] F. B. Churchill, "William Johannsen and the genotype concept," Journal of the History of Biology, vol. 7, no. 1, pp. 5-30, 1974.

[4] A. D. Hershey and M. Chase, "Independent functions of viral protein and nucleic acid in growth of bacteriophage," The Journal of general physiology, vol. 36, no. 1, pp. 39-56, 1952.

[5] S. Arnott, "Historical article: DNA polymorphism and the early history of the double helix," Trends in biochemical sciences, vol. 31, no. 6, pp. 349-354, 2006.

[6] J. Watson, The double helix. Hachette UK, 2012.

[7] J. García et al., "Estrategias de obtención de proteínas recombinantes en Escherichia coli," VacciMonitor, vol. 22, no. 2, pp. 30-39, 2013.

[8] S. Khan et al., "Role of recombinant DNA technology to improve life," International journal of genomics, vol. 2016, 2016.

[9] K. Au - Hansen, M. J. Au - Coussens, J. Au - Sago, S. Au Subramanian, M. Au - Gjoka, and D. Au - Briner, "Genome Editing with CompoZr Custom Zinc Finger Nucleases (ZFNs)," JoVE, no. 64, p. e3304, 2012/06/14/ 2012, doi: doi:10.3791/3304.

[10]P. D. Hsu, E. S. Lander, and F. Zhang, "Development and applications of CRISPR-Cas9 for genome engineering," Cell, vol. 157, no. 6, pp. 1262-1278, 2014.

[11]Y. Ishino, H. Shinagawa, K. Makino, M. Amemura, and A. Nakata, "Nucleotide sequence of the iap gene, responsible for alkaline phosphatase isozyme conversion in Escherichia coli, and identification of the gene product," Journal of bacteriology, vol. 169, no. 12, pp. 5429-5433, 1987.

[12]P. Horvath and R. Barrangou, "CRISPR/Cas, the immune system of bacteria and archaea," Science, vol. 327, no. 5962, pp. 167-170, 2010.

[13]K. S. Makarova, N. V. Grishin, S. A. Shabalina, Y. I. Wolf, and E. V. Koonin, "A putative RNA-interference-based immune system in prokaryotes: computational analysis of the predicted enzymatic machinery, functional analogies with eukaryotic RNAi, and hypothetical mechanisms of action," Biology direct, vol. 1, no. 1, p. 7, 2006.

[14]R. Barrangou et al., "CRISPR provides acquired resistance against viruses in prokaryotes," Science, vol. 315, no. 5819, pp. 1709-1712, 2007.

[15]E. Deltcheva et al., "CRISPR RNA maturation by trans-encoded small RNA and host factor RNase III," Nature, vol. 471, no. 7340, p. 602, 2011.

[16]M. F. Lammoglia-Cobo, R. Lozano-Reyes, C. Daniel, R. B. Muñoz-Soto, and C. López-Camacho, "La revolución en ingeniería genética: sistema CRISPR/Cas," Investigación en Discapacidad, vol. 5, no. 2, pp. 116-28, 2016.

[17]L. E. Giono, "CRISPR/CAS9 Y LA TERAPIA GÉNICA," CRISPR/ Cas 9 and gene therapy., Article vol. 77, no. 5, pp. 405-409, 09// 2017.

[18]Y. H. Díaz and A. A. M. López, "Transformación Genética de Eucariotas," Kuxulkab,' vol. 18, no. 35, 2014.

[19]J. M. Torres, "Terapia génica:¿ Por qué perseverar?," Ludus Vitalis, vol. 16, no. 29, pp. 203-206, 2016.

[20]J. G. Jansen, A. Tsaalbi-Shtylik, and N. de Wind, "Roles of mutagenic translesion synthesis in mammalian genome stability, health and disease," DNA repair, vol. 29, pp. 56-64, 2015.

[21]I.-R. M. Russo et al., "'Intentional Genetic Manipulation' as a conservation threat," Conservation Genetics Resources, vol. 11 , no. 2 , pp. $237-247,2019 / 06 / 01$ 2019, doi: $10.1007 /$ s12686-018-0983-6.

[22]Y. Feng et al., "Targeting Cdk11 in osteosarcoma cells using the CRISPR-cas9 system," Journal of orthopaedic research, vol. 33, no. 2, pp. 199-207, 2015.

[23]C. Long, J. R. McAnally, J. M. Shelton, A. A. Mireault, R. BasselDuby, and E. N. Olson, "Prevention of muscular dystrophy in mice by CRISPR/Cas9-mediated editing of germline DNA," Science, vol. 345, no. 6201, pp. 1184-1188, 2014.

[24]G. Schwank et al., "Functional repair of CFTR by CRISPR/Cas9 in intestinal stem cell organoids of cystic fibrosis patients," Cell stem cell, vol. 13, no. 6, pp. 653-658, 2013.

[25]W. L. Chew et al., "A multifunctional AAV-CRISPR-Cas9 and its host response," (in eng), Nat Methods, vol. 13, no. 10, pp. 86874, Oct 2016, doi: 10.1038/nmeth.3993.

[26]R. Kaminski et al.,"Elimination of HIV-1 genomes from human T-lymphoid cells by CRISPR/Cas9 gene editing," Scientific reports, vol. 6, p. 22555, 2016.

[27]L. Ye et al., "Seamless modification of wild-type induced pluripotent stem cells to the natural CCR5 $\Delta 32$ mutation confers resistance to HIV infection," Proceedings of the National Academy of Sciences, vol. 111, no. 26, pp. 9591-9596, 2014.

[28]V. Ramanan et al., "CRISPR/Cas9 cleavage of viral DNA efficiently suppresses hepatitis B virus," Scientific reports, vol. 5, p. 10833, 2015.

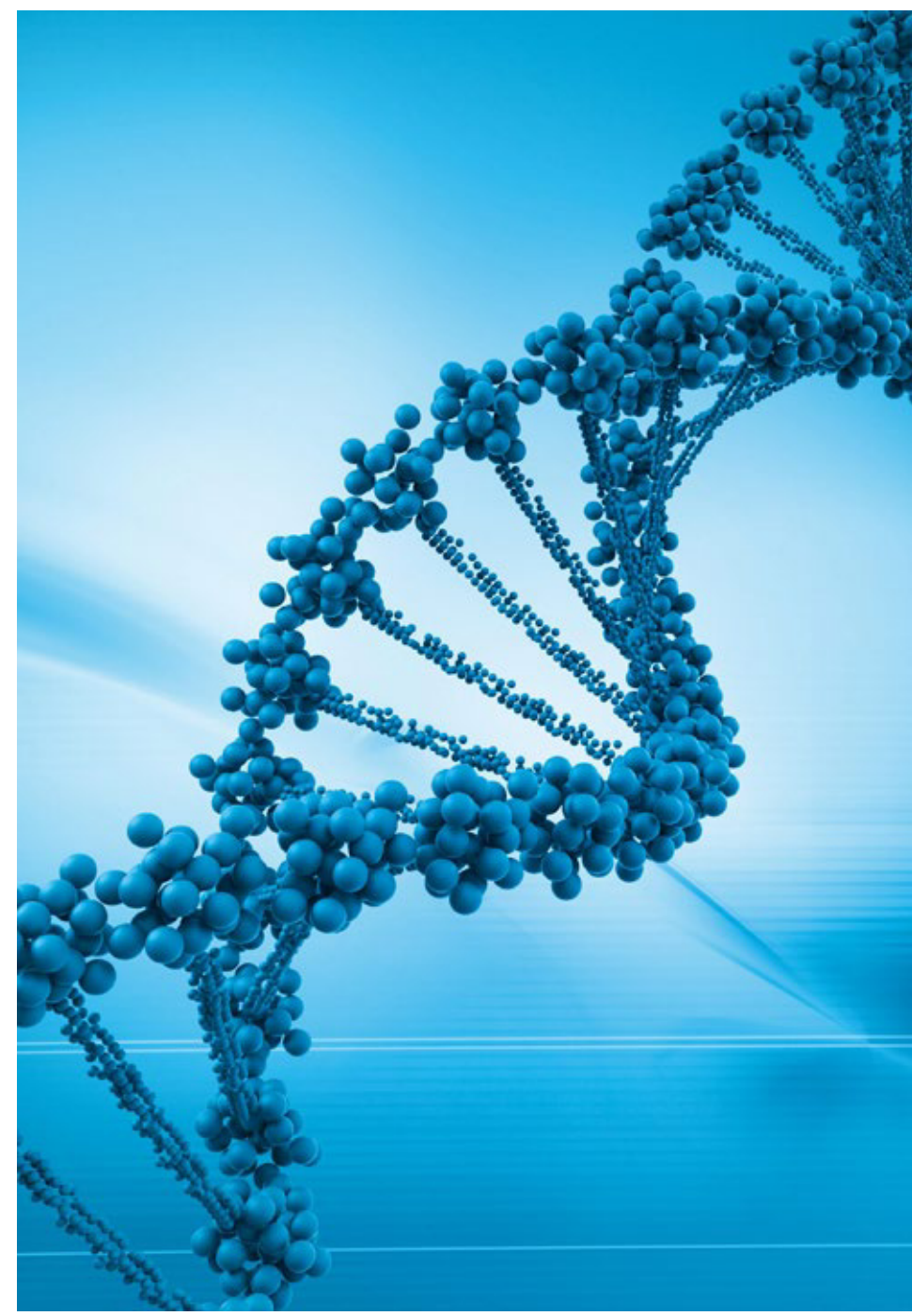

